\title{
The development of an inclusive model to construct teacher's professional knowledge: pedagogic content knowledge for sound-based music as a new subject area
}

Motje Wolf, De Montfort University Leicester

Postal Address: Portland Building 1.23, The Gateway, Leicester LE1 9BH, mwolf@dmu.ac.uk

Sarah Younie, De Montfort University Leicester, syounie@dmu.ac.uk

\section{In: Organised Sound, Volume 24, Issue 3, Dec 2019}

\section{ABSTRACT}

This paper outlines a systematic process for developing the different knowledge domains required for teaching sound-based (electroacoustic) music as a new subject area.

As a new area within the discipline of music, teachers are novices to the field. This requires epistemological deconstruction of what knowledge teachers need in this new field. Then the analysis outlines how to develop teachers' new knowledge; which can be constructed as: subject content knowledge (SCK), pedagogic content knowledge (PCK) and technology pedagogic content knowledge (TPACK).

This epistemological analysis informed our creation of teaching materials that develop these different knowledge domains and take account of the complex interplay between them. This process was demonstrated through the ElectroAcoustic Resource Site Projects to: build first subject content knowledge; then create teacher's packs to build pedagogic content knowledge; and a bespoke CPD programme to embed their inter-relationships and build technology pedagogic content knowledge.

Most importantly, creating the teacher's packs employed a user-centred design approach, putting teachers and pupils in the centre of the development process, thereby giving them voice. Voice is an integral part of empowerment in our model, which is conceptualised as 
practicing 'communicative action' (Habermas 1984) and disrupts the hegemonic grip of the academic curriculum dominated by the tradition music canon.

This paper adds to the knowledge-base regarding how to develop the different domains required for teaching a new subject. We argue that sound-based music is accessible to all teachers and learners, thereby increasing inclusivity. This in turn can radically disrupt ways of teaching music in schools and the model created provides the necessary scaffolding for a paradigm shift in music teaching on an international level. 


\section{Introduction}

Many publications have outlined a knowledge gap between sound-based music (sbm) and societal awareness (Landy 2007, Wolf 2008, 2013a, 2013b, Holland 2016). ${ }^{1}$ This gap is also apparent when examining the National Curriculum for England, where only little guidance is given regarding contemporary music or Music Technology (DfE 2013). Even the National Music Plan (DfE 2011), the current government policy on Music Education, only entails minimal information, relating specifically to Music Technology. However, while sbm inevitably uses technology for music making, it is not its central feature. Hence while technology is needed to make sbm, for the following discussions and to unlock its pedagogic potential, sound will be understood as the driving parameter (Wolf 2013a and b).

Bringing sbm to the classroom will mean teachers ${ }^{2}$ learning a new subject area. Teaching a new topic can be time consuming and challenging. Science teachers often have to manage this to incorporate newly found science knowledge (Chan and Yung 2018). This is a rather rare case for music teachers. Of course, music also develops and contemporary music has entered the classrooms. Many developments in contemporary or pop music, however, can be taught with very similar pedagogic strategies as previously taught content. However, teaching sbm requires novel thinking about the terms sound and music, as well as new strategies to teach the new subject area. Teaching sbm, consequently, provides a challenge for music teachers. Sbm consists of many distinct genres to which many exclusive terms belong. Defining those for researchers and composers of sbm, as happened in the ElectroAcoustic Resource Site (EARS) project of De Montfort University Leicester, has taken many years (Landy 2007). The challenge of breaking this knowledge down to school level and applying suitable pedagogic strategies, however, is the focus of this paper.

1 In this article sound-based music and electroacoustic music will be understood as the same.

2 We focused on specialist music teachers in secondary schools in England with children aged 11 to 14 years, and investigated their teacher knowledge. Consequently, the term 'teacher' in this article is used to mean secondary music specialist teachers. Bearing in mind the international domain of the EARS 2 project, it is necessary to point out that the debate of this article is transferable to international contexts. 
The implementation of a new area within a subject discipline that requires new teaching strategies also requires an in-depth understanding of how teachers learn to teach. So, following the development of the musicological framework, which will be outlined below, one of the tasks was to develop a specific pedagogic knowledge for school-based teachers of sbm. Shulman (1986) identifies this as pedagogic content knowledge (PCK). This is a specific type of teacher knowledge and defined by Shulman (1986: 8) as 'that special amalgam of content and pedagogy that is uniquely the province of teachers, their own special form of professional understanding'. Therefore if a topic has not yet been mapped educationally for school curricula delivery, this pedagogic content knowledge still needs to be established after the development of the content. Pedagogic content knowledge can further be defined as

... a distinct knowledge base that encompasses a teacher's understanding of how to help students understand specific subject matter. It includes how particular subject matter topics, problems and issues can be organised, represented and adapted to the diverse interests and abilities of learners and presented for instruction. (Magnusson et al. ,1999: 96 cited in Chan and Yung 2018: 234).

Throughout this paper, the pedagogic potential of sbm will be analysed, followed by an in-depth investigation regarding interplay of the different knowledge domains of sbm in an educational context. This will be carried out introducing two projects that supported the knowledge development (EARS 2) and subsequent management (Music MESHguides). We will propose a model of constructing teacher's professional knowledge, focusing on pedagogic content knowledge for sbm. The relation of sbm and teachers' professional knowledge is analysed through the theoretical framework of the Frankfurt school in section 2.2.

\section{The pedagogic potential of sound-based music}

In this section, we will discuss the pedagogic potential of sbm. Hence, we will introduce previous research connected to the pedagogy of sbm investigating why this pedagogic 
potential matters. For this, we are going to apply Bourdieu's (1976) theory of cultural capital to school music curricula and sbm in section 2.2.

In this article, different projects with similar names will be referred to. Table 1 provides an overview. In order to distinguish between the original EARS project and the follow up project EARS 2, EARS will be called EARS 1 for this article only.

\begin{tabular}{|l|l|l|l|}
\hline Project & Definition & Focus & Research \\
\hline EARS 1 & $\begin{array}{l}\text { Electro-Acoustic } \\
\text { Resource Site } \\
\text { Project }\end{array}$ & $\begin{array}{l}\text { Glossary of terms for } \\
\text { researchers and composers of } \\
\text { electroacoustic music }\end{array}$ & Landy (2007) \\
\hline $\begin{array}{l}\text { Prototype of the EARS } \\
2 \text { project }\end{array}$ & $\begin{array}{l}\text { PhD project by Motje } \\
\text { Wolf }\end{array}$ & $\begin{array}{l}\text { E-Learning Environment and } \\
\text { curriculum for 11-14 year old } \\
\text { pupils/novices to the field }\end{array}$ & Wolf (2008) \\
\hline $\begin{array}{l}\text { EARS 2 } \\
\text { www.ears2.dmu.ac.uk }\end{array}$ & $\begin{array}{l}\text { pedagogic } \\
\text { ElectroAcoustic } \\
\text { Resource Site }\end{array}$ & $\begin{array}{l}\text { E-Learning Environment and } \\
\text { curriculum for 11-14 year old } \\
\text { pupils/novices to the field } \\
\text { Teacher's packs }\end{array}$ & Landy (2012) \\
& & & $\begin{array}{l}\text { Landy, Hall and } \\
\text { Uwins (2013) }\end{array}$ \\
& & & $\begin{array}{l}\text { Landy, } \\
\text { Younie, Hill and } \\
\text { Wolf (2014) }\end{array}$ \\
\hline
\end{tabular}

Table 1 Overview of EARS projects

\subsection{Music Education Research with Sound-based Music}

$\mathrm{Sbm}$ has been a focus of educational research for many years with a research centre established at De Montfort University in the Music Technology Innovation (MTI²) Department. Synthesizing the doctoral research from Holland (2016), Wolf (2013), and Therapontos (2013), allows us to argue that sbm has pedagogic potential, which offers something truly unique and innovative into the school music curriculum.

Previously research regarding music technology focused on the effect of technology added to music (Bolton 2008, Burnard 2007, Savage 2005). However, as outlined above, while sbm may utilise technology, our focus is on making music with sounds rather than on the technology. 
Wolf (2013a) tested young people's appreciation of sbm in England, through developing and teaching a curriculum for sbm. The curriculum, the prototype of the EARS 2 project, was presented within an e-learning environment. The study found that those children, who would like to listen again to sbm, also stated that their listening ability had changed following a listening training. This shows that access to this music was gained through learning to listen to sounds in musical ways (such as 'reduced listening'). ${ }^{3}$ Therefore, this concept in the pedagogical context was later called 'musical listening'. Alongside Wolf's (2013a) doctoral research, Therapontos' (2013) thesis investigated the implementation of sbm in schools in Cyprus, stating that sbm provided an inclusive education. Further developments from Holland (2016) found that pupil engagement increased in all classes following his method of heightened listening training.

In order to understand the significance of the pedagogic potential this has been analysed through the theoretical framework of the Frankfurt School of critical theory.

\subsection{Social and cultural reproduction: school music curricula and sound-based music}

Bourdieu's (1977) analysis of the school as a site of social reproduction can be understood in terms of analysing how the curriculum privileges those students in possession of cultural capital. Middle-class pupils' success with an academic school curriculum, including the classical music canon is a function of their 'cultural capital' and 'habitus'. Such pupils' motivations to learning, their dispositions and attitudes, parental support, linguistic skills and access to high culture privileges them to engage comfortably with it, resulting in a correspondingly high uptake. Contrastingly, those from different 'habitus' with lower 'cultural capital' are more limited. Vincent and Ball (2007) showed that music is a class-dependent enrichment activity with middle-class families being more likely to take this up. This is not only applicable to the English education system, but also holds true for international music education.

3 The authors are aware of the problematic notion of 'reduced listening' due to the great difficulty of ignoring the source of a sound, however, discussing this is beyond the scope of the article. 
This important theoretical lens enables us to explain and understand that despite the same national curriculum may be offered to all pupils and presented as an equality of opportunity for all, it nonetheless produces differential outcomes, such that the status quo remains unchanged. Society therefore continues to be culturally and socially divided and replicated. The connection of social class and the curriculum has been discussed in great detail by Marxist theorists (Adorno 1970, 1991, Horkheimer 1938, Marcuse 1937 (Frankfurt School of critical theory), later development: Bowles and Gintis (1976), Poulantaz (1975) and Willis (1977) in UK and US). This analysis renders the curriculum as performing an ideological function in reproducing social and cultural inequality. Therefore, there is a perpetuation with cultural capital among middle-class pupils, allowing them to have a continuing advantage over those with lower cultural capital. Thinking about music, this might result in some pupils who think that music is not for them.

Bourdieu's (1977) theory of 'cultural capital' states that the more affluent classes have greater access to resources (economic capital) and social codes (developing good manners), but most importantly, this applies to accessing high culture, which includes appreciating traditional classical music. Griffiths (under review) discussed who and who is not admitted to the canon with the example of female and BME composers. Griffiths analysed concert programmes of major English orchestras, the London Proms and of one week across two classical radio stations, showing that white composers were played most ( $99 \%$ of the pieces). Similarly, for gender, only $2 \%$ of the pieces were by female composers. This demonstrates a systemic problem of access to the music elite. This division has developed over time and is perpetuated in the classroom. The music classroom is mixed with children who have had private music lessons and those without any musical training. This creates an imbalance of knowledge and skills, making music teaching challenging due to differences in prior knowledge (and cultural capital) levels of music. 
It is a stretch to reach the more able whilst keeping the rest of the class engaged. This creates a situation of great diversity which can be investigated further through applying Bourdieu's (1976) concept of 'cultural capital' and 'habitus'. Consequently, children without the 'right' level of cultural capital get excluded from the opportunities to creatively engage in music and the arts in general. Valenzuela and Codina (2014) showed primary school children who had prior musical knowledge demonstrated a higher engagement and motivation in their music lessons. Contrastingly, Holland (2016) showed that with sbm, while children with prior musical training might use different strategies to compose music, both groups (with and without prior musical training) showed similar levels of engagement.

That music is more accessible for learners addresses Bourdieu's (1976) critique of exclusion based on the level of cultural capital. There is a disparity between social classes that is expressed through the difference in economic capital. However, it also is established through the possession of cultural capital which can be summarised as symbols of belonging to a class, such as certain types of knowledge, skills and values: simply put, families reproduce cultural capital through privately educating their children, including instrumental/vocal music lessons. This way, children learn the traditional canon of classical music, allowing them to engage in high culture and the academic curriculum with the appropriate socio-epistemic codes. This is again in line with the findings of Vincent and Ball (2007). Another interesting discussion can be found in Albert (2006) who also links high socioeconomic status with a higher likelihood of uptake and retention of instrumental music lesson.

Furthermore, innovation is needed to enable more children to access music lessons and subsequent creative engagement with music. We argue that sbm has the potential to do this by creating a level playing field whereby no prior musical knowledge is needed to engage with this new curriculum. However, crucial to this, is the ability of teachers to deliver this new subject area. Thus, following Habermas's $(1984,1987)$ concept of communicative action, we enable teachers to disrupt this hegemonic grip. 
In moving towards a more culturally diverse curriculum, for example through sbm, the privileging of the music canon is disrupted and enables a wider participation by pupils of greater diversity, not only those who possess social and cultural capital. In this sense, the struggles over cultural diversity in the curriculum (along the lines of class, gender and race, whereby certain topics get silenced, such as Black history (Gilroy 1987) and gender studies (Walby 1990)), a rupture can challenge the hegemonic grip of the traditional academic curriculum. To this end, the authors adopt Giroux's (1983) analysis that the curriculum should be treated as a 'contested terrain'.

To contest the current music curriculum, teachers need to know how to teach sbm as an extension to the traditional canon. Hence, this article investigates the teacher knowledge needed to enable children to engage in musical activity without prior cultural capital in music. This way, combined with the EARS 2 teacher's packs, we claim to provide an answer to the question Valenzuela and Codina (op.cit) posed at the end of their article regarding; the extent to which it is possible for primary school music teachers to foster 'new' musical cultural capital and a 'new' autonomous engagement in musical practice, when there is originally none in the family, or when the family is not supportive of this practice (Valenzuela and Codina, 2014, p 519).

\section{Knowledge types in sound-based music teaching}

In 2.1, we analysed the pedagogical potential of sbm and why this knowledge is not part of the academic canon. This section will go deeper into the epistemological discussion and the knowledge domains that teachers require.

\subsection{Curricular of conservatoires and universities: the subject knowledge of music degrees}

Music teachers predominantly gain their knowledge-base for teaching during their university education. Wolf (2008) found that electroacoustic music in Germany, Austria and Switzerland is only marginally part of the curriculum of the degree programmes of 
conservatoires and universities. An overview of the teaching programmes of all universities/conservatoires is published in the journal of the Gesellschaft für Musikforschung. Wolf added up 1276 modules and of those, 97 module topics related to electroacoustic music. Of these 97 modules, 48 took place at one university - showing very limited spread of electroacoustic music across higher education in those countries. While we appreciate that this data needs to be updated and we do not have this same information for the UK, we cannot comment on whether the situation has improved. Nevertheless, teachers who studied in 2008 are now the teachers who are delivering the music curriculum in schools.

This shows that there is a need for music content knowledge to be updated; teachers will access sbm afresh. Consequently, it is important to establish what knowledge is needed for the teachers to successfully teach sbm and thereby enable all children to engage in musical activity.

\subsection{Professional knowledge for teaching sound-based music}

Shulman (1986) proposed seven types of teacher knowledge that teachers need to know to effectively teach: see Figure 1

Shulman (1986) argues teachers need professional knowledge for teaching; of which there are different types, but the key knowledge domains that we focus on are subject content knowledge (SCK), general pedagogic knowledge (GPK) and pedagogic content knowledge (PCK). Subject content knowledge is the content to be taught, which consists of the substantive concepts and skills of a subject and syntax (the organisation of these concepts and skills). Next, teachers need to have professional knowledge of pedagogy, which refers to knowing a range of teaching and learning strategies, referred to as general pedagogic knowledge; these will include class management skills, which will apply irrespective of the curriculum subject taught. Pedagogic content knowledge refers to knowing how to teach specifically the subject and how to ensure learning of subject conceptions (Capel, Leask and Younie, 2016). 


\section{1. (Subject) Content Knowledge}

2. General Pedagogic Knowledge

\section{Curriculum Knowledge}

\section{Pedagogic Content Knowledge}

5. Knowledge of Learners and their Characteristics
6. Knowledge of

Educational Contexts
7. Knowledge of Educational Ends (aims)

(adapted from Shulman, 1986 cited on p.18 Capel, Leask \& Younie (2016) Learning to teach in the secondary school: a companion to school experience Abingdon: Routledge)

Figure 1 Teacher Knowledge

Importantly, teachers are required to transform the knowledge they possess about a subject (SCK) into appropriate tasks that enable learning, through utilising general pedagogic knowledge (GPK) and developing specialised pedagogic content knowledge (PCK). In this way, music teachers' design of teaching and learning will be different to maths teaching and learning, and other subjects. However, this also means that when a new subject area needs to be included into a discipline, new pedagogic content knowledge needs to be developed. Shulman (1986) argues PCK includes:

... The most useful forms of representation of [subject topics], the most powerful illustrations, examples, explanations and demonstrations - in a word, the ways of representing and formulating the subject that makes it comprehensible to others...Pedagogical content knowledge also includes an understanding of what 
makes the learning of specific topics easy or difficult: the conceptions and preconceptions that students of different ages and backgrounds bring with them to the learning (Shulman 1986: 9).

Subsequently, we need to specify more detail regarding the content knowledge of sbm and the pedagogic content knowledge required for sbm. Therefore, we analyse how the knowledge and the level of scaffolding needed to develop pedagogic content knowledge for a teacher can be created.

\subsubsection{Subject content knowledge - for sound-based music}

From EARS 1 to the prototype of the EARS 2 website - musicological frameworks Analysing the subject content knowledge of a musical field, inevitably leads to musicological frameworks. The field of electroacoustic music consists of many new genres and associated terms. A glossary of terms was created by established researchers and composers led by Leigh Landy and Simon Atkinson to define terms and genres related to sbm, which was published on EARS 1 website. The ElectroAcoustic Resource Site project (EARS 1) distinguished between six areas:

1. Disciplines of Study

2. Genres and Categories of Electroacoustic Music

3. Musicology of Electroacoustic Music

4. Performance Practice and Presentation

5. Sound Production and Manipulation

6. Structure, Musical

These areas are discussed in-depth in Landy (2007), who presented with this book a seminal discussion of the subject knowledge of the field. The process of defining the terms for the glossary was the first knowledge repository widely accepted amongst researchers and composers. In light of the development of EARS 1, Landy (2007) put 
forward a framework for the study of 'sound-based art works' based on the work of Pope (1996). Pope suggested the following categories:

1 Music Theory, composition, and Performance

2 Music Acoustics, psychoacoustics, perceptions, and cognition

3 Musical signal and event representation and notation

4 Digital control and sound signal synthesis and processing

5 Hardware support for computer music

6 Computers in music education and computer music education

7 Computer music literature and sources

Looking closer into category 6, no more detail was available but the header. Therefore, we can draw the following conclusion: Pope (1996) already was aware of the differentiation of teaching Music Technology (Computers in Music Education) and teaching Music with technology (Computer music education). The category was either not yet developed or at this stage not important enough to be discussed further. Landy (2007) then concentrated on the musicological (rather than educational) questions and dropped this category in his framework in 2007. Hence, Landy's suggested musicological framework is:

1 Classification: from sound to work level

2 The listening experience

3 Modes of discourse, analysis, and representation

4 organizing sound from micro- to macro-level

5 New virtuosity

6 New means of presentation

7 Achieving interdisciplinarity and holism (Landy 2007: 188)

With the start of designing the prototype of the pedagogic ElectroAcoustic Resource Site Project (EARS 2), it was possible to expand Pope's (1996) educational category. Now, just over ten years on, we can define the different types of knowledge that pupils and teachers need to develop to learn and understand sbm in school. 
The prototype of the EARS 2 curriculum, being an educational project addressing pupils rather than researchers, a new framework was needed. This was based on the original terms on the EARS 1 website. As the prototype of the EARS 2 curriculum information addressed novices (initially equivalent to the English System Key Stage 3, 11-14-yearold pupils but developed with international application in mind), a reduction of terms and concepts had to happen. Subsequently, three areas were created following a top-down and bottom-up approach of analysing the terms.

Two questions guided this process:

-What is absolutely necessary to know?

-What might spark and retain the interest of the target group?

Then two rules were applied to the prototype of the EARS 2 curriculum content: Use only those terms from EARS 1 which are related to each other and understandable for children without extracurricular knowledge. In that light, soundscape and soundwalk were included as they are relating to each other. However, acoustics requiring a higher level of physics knowledge were not included (Wolf 2013a).

The curriculum was developed independent from any cultural capital that children might bring to the classroom and therefore is inclusive and does not rely on extracurricular/ prior musical knowledge. Continuing with the idea of musicological frameworks from the previous section, a smaller framework was developed by adapting Landy's framework.

The knowledge was then classified further into three categories according to Anderson and Krathwohl's revised taxonomy (2001): factual, conceptual and procedural knowledge. This has been outlined in Wolf (2013b). This helped to get an understanding of the function of the different types of knowledge and provided the base for creating assessment. 


\begin{tabular}{|c|c|c|}
\hline Classification of sounds & Listening Experience & $\begin{array}{l}\text { Modes of Discourse, } \\
\text { Analysis, and } \\
\text { Representation }\end{array}$ \\
\hline $\begin{array}{l}\text { real-world sounds and } \\
\text { generated sounds (from } \\
\text { sound to music) as starting } \\
\text { point for the research and } \\
\text { the pedagogical concept } \\
\text { of the curriculum }\end{array}$ & $\begin{array}{l}\text { reduced listening and } \\
\text { referential listening as a } \\
\text { starting } \\
\text { point for the learner - } \\
\text { listening is the first way they } \\
\text { come in contact with } \\
\text { electroacoustic music }\end{array}$ & $\begin{array}{l}\text { aural analysis and } \\
\text { graphical } \\
\text { representation of } \\
\text { sounds }\end{array}$ \\
\hline $\begin{array}{l}\text { Real-world sounds } \\
\text { Generated sounds }\end{array}$ & $\begin{array}{l}\text { Listening Strategy } \\
\text { Source Recognition and } \\
\text { Source Bonding } \\
\text { Referential Listening } \\
\text { Reduced Listening and } \\
\text { Acousmatic. }\end{array}$ & $\begin{array}{l}\text { a) Aural Analysis and } \\
\text { b) The use of graphical } \\
\text { representation of } \\
\text { sounds as educational } \\
\text { tool. }\end{array}$ \\
\hline
\end{tabular}

Table 2 Musicological Framework (Wolf 2013a) for the prototype of the EARS 2 project

Following this systematic approach of content development, we discovered that while one gap was filled at this stage (SCK), another gap was made apparent: there was no instruction of how to teach this in a classroom (PCK). However, the foundations of pedagogic content knowledge were established in the prototype of EARS 2 by the creation of tutorials whereby the content of the website was combined to short courses that the learner could complete. This provided scaffolding (Bruner, 2006) for learners to work their way through the content information.

The extension of the curriculum: EARS 2

Following the development of the prototype, the pedagogic ElectroAcoustic Resource Site (EARS 2) project grew into a team of researchers, composers and technologists led by Leigh Landy at the $\mathrm{MTI}^{2}$. The authors of this article were responsible for the pedagogic usability of the content and the development of teacher's packs. Additional content was added, a new composition software developed (Compose with Sounds) 
and new projects (formerly in the prototype called tutorials) were structured. After completing a short introductory project, the learner can go through three topic routes: real-world sounds, manipulated sounds, and generated sounds - each topic having three proficiency levels: beginner, intermediate and advanced.

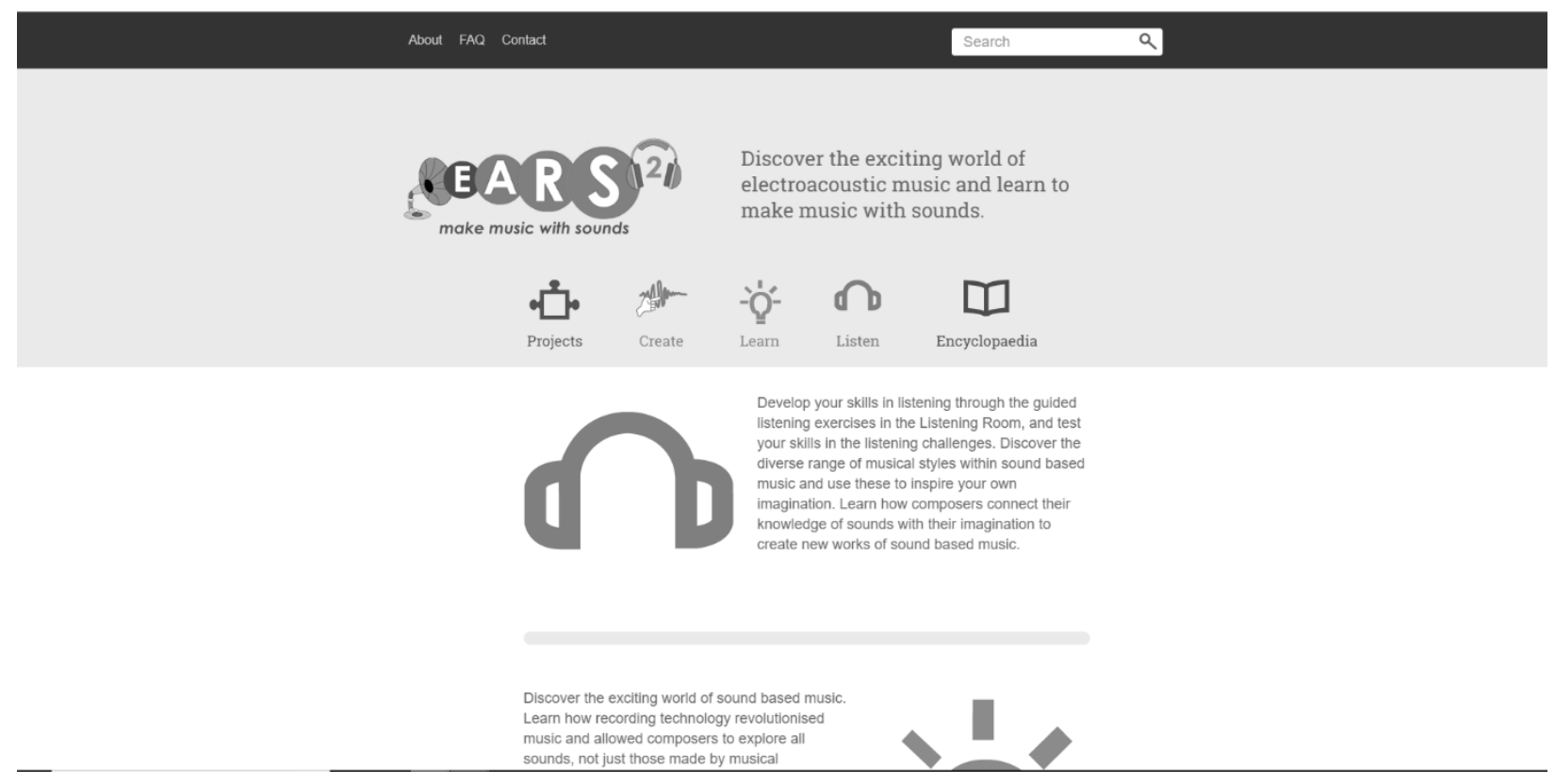

Figure 2 Screenshot of the EARS 2 website

The EARS 2 project is available for use in different countries. Internationalisation included not only the translation of the words, but also an adaptation of the pedagogic content knowledge and the choice of sounds to ensure cultural relevance for other countries. This process of cultural adaptation again aids the accessibility of the knowledge. This way, the hegemonic grip of exporting Western knowledge to other countries can be interrupted. The Chinese version of EARS 2, CHEARS (www.chears.info), is currently under development.

Additional to the content knowledge that can be found on the website, teacher's packs were developed that were providing an explanation of the content knowledge and the pedagogic content knowledge for the teacher. Section 3.2.2 provides further detail. 


\subsubsection{Pedagogic content knowledge applied to the content knowledge: the development of the Teacher's Packs}

Having established the overview of the necessary content knowledge, there is a notion within the field that there is a lack of research into 'how to teach' music (Jaramillo 2008: 348), which we see as referring to pedagogic content knowledge (PCK). This, specific, PCK is difficult to capture. Listing content knowledge is a straightforward activity, however, even though Shulman (1987) describes PCK as a distinct body of knowledge, it is difficult to list; it is more implicit knowledge of how to present the content knowledge in an appropriate way to learners.

With the help of the teacher's packs, a bridge between the EARS 2 website resource and the classroom was created, aiming to support teachers to use EARS 2. Essentially, this created a longer bridge from the original EARS 1 project of subject content knowledge to the pedagogic content knowledge needed in the classroom.

The EARS 2 Teachers' Packs aim to bridge the gap between the EARS 2 learning environment and the teacher by offering a pedagogically structured approach to each of the existing learning projects on the EARS 2 website. Therefore, they act as mediator between learning tool and learning facilitator offering teaching support in form of lesson plans and ideas for further planning (such as cross-curricular teaching, and extended learning activities).

The packs were developed together with a teacher, see 4.1. With respect to listening to the teacher's feedback on the teacher's packs, we were mindful to adhere to the teacher's suggestions as the process of implementing content into teaching and learning is complex. The pedagogic implementation of sbm content required teachers to engage with the practicalities of delivering the content. This process is not to be underestimated as teachers need multiple strategies to teach concepts as not all learners learn in the same way. As Shulman (1986: 9) notes, '...the teachers must have at hand a veritable armamentarium of alternative forms of representation' which derive 
from resources and research on the subject and also come from 'the wisdom of practice'.

The teacher's pack starts with an introduction outlining the aims of the National Curriculum for Music (Key Stage 3), the standard resources and requirements. Then a summary of the pack is provided, including some notes on assessment and a skills map. Options for cross-curricular teaching are also presented and discussed. Then all units are presented in the following structure:

1 Summary

2 Aim

3 Resources

4 Time

5 Prerequisites

6 Preparation

7 Links to the National Curriculum

8 Learning Outcomes

9 Step-by-Step Procedure

10 Extended Learning Activity

11 Assessment

12 Teacher's Tip

With the exception of the shorter introduction pack, all teacher's packs contain six units of work with a duration of 60 minutes each. 
Figure 3 Screenshot Teacher's Pack

\subsubsection{Technology Pedagogy Content Knowledge (TPACK)}

Teaching sbm inevitably includes teaching the technology that comes with this subject area. This is not necessarily specific just for music teachers: as technology has developed rapidly, all teachers need to understand how digital technologies have affected their subject and lead to advancements in their discipline fields. Hence, we argue that Shulman's model of the different types of professional knowledge needed by a teacher must be updated and include an additional domain of technology knowledge. In 2006, Mishra and Koehler extended Shulman's model to include the following subdomains: technology content knowledge (TCK), technology pedagogy knowledge (TPK) and technology pedagogy content knowledge (TPACK). This is a further type of knowledge that needs to be developed by a music teacher, especially when teaching sbm. 


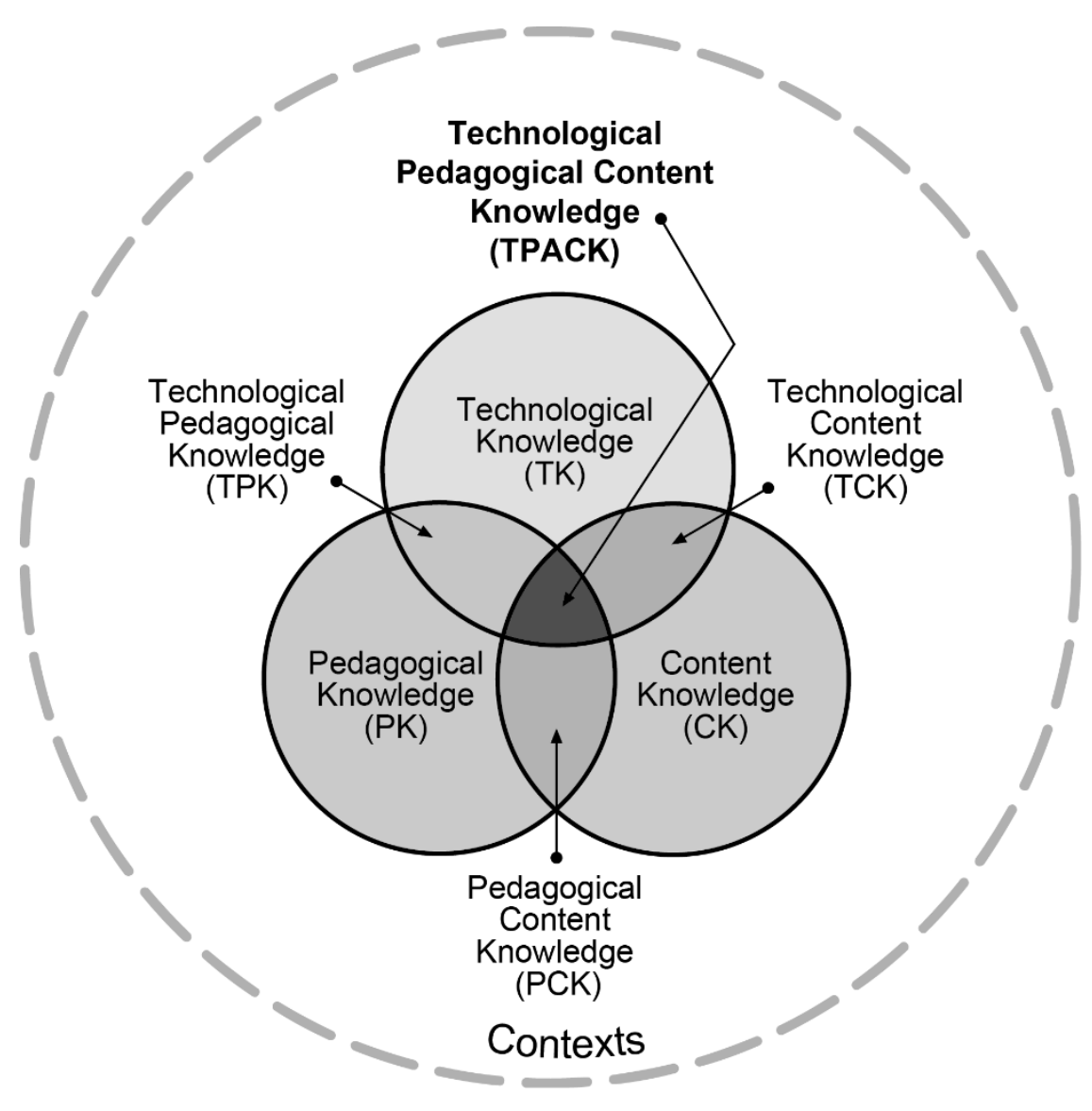

Figure 4 TPACK

In Figure 4, TCK is understood as technology content knowledge: knowledge of the relationship between the subject and technology (how technologies have contributed and advanced knowledge within a subject discipline). Technology pedagogy knowledge (TPK) is the knowledge of how technology can be integrated into learning and teaching (the pedagogical affordances of technology). Technology pedagogy content knowledge (TPACK) entails the understanding of the relationship between all the domains, including the complexity of the interplay between them. Younie's (2007) longitudinal research with 116 teachers showed that teachers' capacity to change pedagogic practice was dependent not only on their knowledge of technology, but also their TPACK, which must be understood as multidimensional and dynamic in relation to the other knowledge domains. 
The centre of the Venn diagram of Figure 4 identifies TPACK as:

A contingent, flexible kind of knowledge that lies at the intersection of these knowledge bases, requiring teachers to develop deep, complex, fluid and flexible knowledge of all three components of the framework. (Koehler et al. 2011: 149).

This demonstrates not only the different types of professional knowledge that teachers need, but also the complex interrelationships between the varying domains of knowledge. Thinking of the sudden expectation of a music teacher to become also a technician when using music technology, this is an interesting model to shed light on what exact knowledge is needed to teach effectively. This extension of Shulman's (1986) model presents a unique way of examining the pedagogic discussion of sbm. TPACK is an integral part of teaching sbm. The EARS 2 project and hence the teaching of sbm is based on a complex combination of subject content knowledge, pedagogic content knowledge and technology pedagogy content knowledge. Therefore, we cannot expect a teacher to teach sbm without significant scaffolding and further CPD.

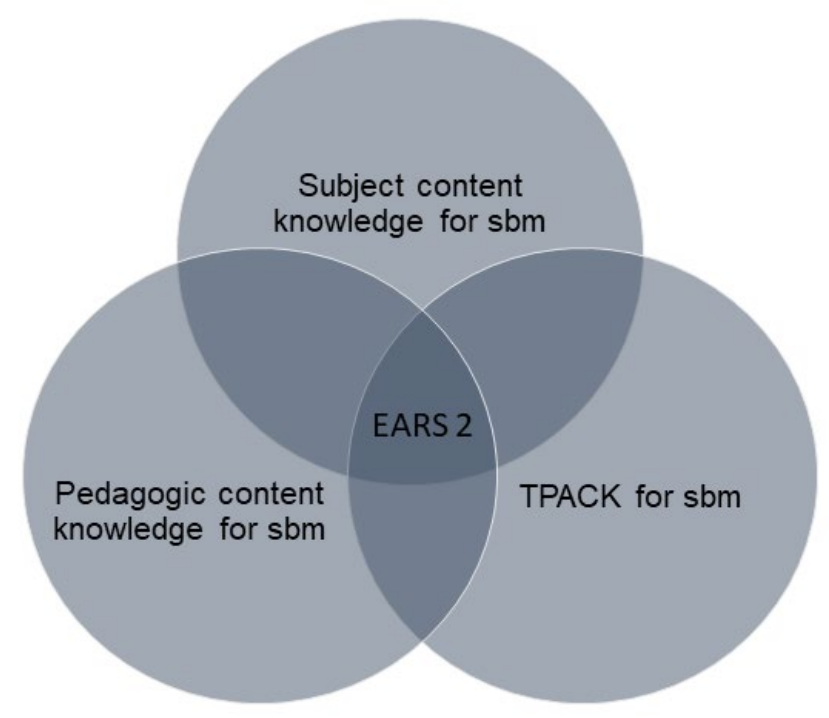

Figure 5: The combination of knowledge types within the EARS 2 project 


\subsubsection{Continuing Professional Development (CPD) for sound-based music}

Following the development of the teacher's packs, a first trial in schools was carried out. This trial was successful in terms of the pupils' engagement and feedback. However, we encountered a missing link between sbm content and enabling teachers to teach sbm in schools (Wolf and Younie, 2018). This was then addressed through the development of a CPD model (ibid). Apart from the delivery of content knowledge and pedagogic content knowledge, this CPD model addresses also the development of a cognitive prototype for sbm which is required by the teacher to deliver sbm effectively.

The CPD model introduces five essential elements:

1 The first element was the decision by the researchers 'to teach' the teachers the content of one project and in parallel to this, provide a teacher's pack providing the pedagogic content knowledge. This needs to be contextualised with conversations around the new sbm topic.

2 The less obvious but important element was to help teachers to develop a cognitive prototype for sbm. This was found to be crucial for pupils in Wolf (2013a) and it had become apparent that although there was content knowledge on the website and pedagogic content knowledge in the projects and teacher's packs, there was no opportunity for teachers to encounter sbm and learn different listening strategies in a structured way.

$3 \mathrm{~A}$ further element was the development of metacognitive knowledge. While we had assumed that the teachers would be able to teach themselves, it became apparent that this was more difficult than anticipated. Therefore, the CPD model included metacognitive development which happened during the listening training as well as implicitly throughout the CPD course.

4 The last element is the building a community of practice. As music teachers often have no, or only a few, colleagues, this was seen as a critical element of enabling teachers to overcome barriers.

5 Further to the above, also TPACK knowledge is given to the teachers during the CPD session. 
This is a stand-alone model, however, EARS 2 can be used within in order to provide the content knowledge. A more detailed discussion on this model, especially elements 1-4, can be found in Wolf and Younie (2018).

\section{Constructing pedagogic content knowledge for teachers}

The next section will discuss the rationale of the approach of designing the teaching material in the teacher's packs. Adopting a user-centred design (UCD) approach, this allowed us to integrate first the pupils' and then the teachers' voices into the development of the materials. This way, it was ensured that the resource was understandable and usable for pupils and teachers and most importantly, allowed for inclusivity, helping to ensure accessibility irrespective of the level of prior music knowledge and cultural capital.

\subsection{Rationale}

Following Younie's (2007) research, we know that that to change teachers' pedagogic practice, a number of factors have to be in place. The material needs to be meaningful, the teachers need to have ownership and the level needs to be appropriate for both teachers and learners. Applying this practitioner knowledge to the EARS 2 content, this meant that the new teaching materials needed to be made meaningful to the teacher through involving them in every step in the development process. This ensured that the teacher has ownership, that the content is appropriate and set at the right level, avoiding mistakes through constant feedback. The feedback loop forms an integral part of UCD, which was the approach we adopted in the development of the teacher's packs; giving teachers and learners voice in the creation of the teaching materials.

Models of creating new teaching materials has been discussed in great detail in Tomlinson (2011). While all the models agree that the development process does need to include the teacher, none of these models specifically uses (or discusses) usercentred design. 


\subsection{User-Centred Design}

User-Centered Design (UCD) can be defined as an iterative process to design a product by collecting feedback from the user within the development process. This was expanded on by the Institute of Design at Stanford University (d.school) who brought forward five steps of UCD: 'empathize, ideate, prototype, test, and refine' (d.school 2010, cited in Shivers-McNair et al., 2018: 38). Furthermore,

'usability [can be defined] as a process of "anticipating users" needs and expectations, as well as designing texts, documents, systems, platforms, spaces, software - and many other things - with a purpose in mind that is appropriate to and tailored for that audience of users' (Miller-Cochran and Rodrigo 2009: 1, cited in Shivers-McNair 2018: 38).

While UCD focused initially on physical product design, it has increasingly been used for website design. Brown (2008) showed how this was done with websites for museums pedagogy. This was the inspiration to try UCD for the EARS 2 project. However, by applying it to such a complex project and using it to design new teaching materials, we bring forward a methodological innovation.

UCD has been a fundamental element of the development of the teacher's packs. We know that a learning resource which does not meet a learner's needs will be unusable, hence the learner was integrated from the first developmental stages of EARS 2 prototype. During the teacher's packs development, input and advice from a teacher was sought. This provided a way of ensuring that both the content knowledge and the pedagogic content knowledge was meaningful to teachers.

A more detailed account of the different test phases of the learning environment can be found in Wolf (2013a), therefore, in this article we focus on the teacher's pack development. The presentation of the process and results follows the five steps of UCD as outlined above: empathise, ideate, prototype, test, and refine. 


\subsubsection{UCD in the Development of the EARS 2 Prototype (online learning environment)}

The prototype of the EARS 2 learning environment was tested following user-centred design in two steps. The first step was to test the initial ideas of navigation and design of the online environment in which the new curriculum would be presented.

Empathise: In this step, an analysis was undertaken how the target group of 11-14 year old children engage with the web.

Ideate and Prototype 1: A first mock-up of how the online environment would look was presented in a paper format to show the target group. This idea was taken from rapid prototyping (Krug 2000) and successfully carried out. Furthermore, the participants of the first test phase were asked to draw their own music learning website, and ideas from there were incorporated into the project.

Test and Refine 1: A first test phase was carried out with the target group. The paper mock-up was shown to the participants showing that both the navigation and the design of the learning environment worked. This was a systematic testing process, asking the questions 'What is this website about and what can you do on this website'. No refinements were needed.

In a second test phase, the content of the curriculum was tested independent of the navigation and design of the learning environment.

Ideate and Prototype 2: The content of the curriculum was uploaded into a neutral wiki environment to avoid bias caused by like/dislike of the navigation and design of the environment. Furthermore, pedagogic ideas taken from test phase 1 were tested here. Test and Refine 2: The participants were given a quiz of 10 questions that they had to solve without any help from the researcher. For this they had to read content that was on the wiki environment. The participants were observed during their time solving the quiz. Nine out of ten questions worked well, consequently, the tenth question was dropped as none of the participants solved it. 


\subsubsection{UCD in the Development of the Teacher's Packs}

Teacher's Pack Study

A small-scale study was conducted to develop the teacher's pack. This study

investigated in what way the teacher's packs combined with the web-based learning environment were sufficient for a teacher who was new to the topic to teach about sbm. This is part of the user-centred design and development process of the material and followed the methodology of action research (McNiff and Whitehead 2010). In a collaborative approach, working with the teacher, the initial material was provided by the research team and was discussed in three meetings with a secondary music teacher. After each session the teacher's feedback was used to improve the teaching material.

The development of the teacher's packs using UCD was undertaken in the following way:

Empathise: A number of teacher's packs from projects around different types of media, such as the Tate Gallery's Movie Project (2011), were accessed and analysed. Furthermore, teaching resources need to be easily accessible, as research with teachers has shown that they are under considerable time constraints, which makes it difficult for them to change their pedagogic practice (Younie 2007).

Ideate: Different ideas for the structure and pedagogic activities of the teacher's pack were brainstormed and brought into a format for the first prototype.

The ideas for the teacher's pack were informed by three guiding principles synthesising our own (over 30 years of) pedagogic experience, research and teaching practice:

- materials had to be easily accessible by teachers;

- materials would support the teacher's classroom practice;

- materials would stimulate new and innovative classroom activities and discussions.

Prototype: Two prototype teacher's packs, Soundscape (now: Real-world Sounds) and Acousmatic Music (now: Manipulated Sounds), were written. 
Test and Refine: Testing and refining happened in three cycles in which material was shown to a KS3 music teacher and adapted according to their feedback. Two interviews were conducted at the end of each cycle and one interview after a classroom trial. The teacher was shown the prototype of the teacher's pack 'Soundscape Beginner'. Questions were asked regarding the interplay of the website and the teacher's pack, the layout of the teacher's pack and usability. Further questions investigated the navigation through the content of the teacher's pack.

The teacher's feedback was rich, detailed, and overall positive; however, some constructive criticism was voiced aiding further development.

\section{Feedback on the EARS 2 website:}

The website was valued, especially the layout and use of graphics. The navigation was easy to understand for the teacher and pupil-friendly. As the website had already undergone intensive testing, this was reaffirming after the expansion of the website.

The website includes a sound-bank for teachers to download to support activities in the projects; this was seen as positive. However, the teacher suggested that some of the language was too technical and needed to be simplified.

\section{Feedback on the teacher's packs:}

The teacher emphasised that the pack was user-friendly as it had the appropriate amount of text for a busy teacher to read, linking back to the guiding principles of the development. The packs were found to integrate well with the website, so it was clear which pack linked to which project on the website.

Constructive criticism was given for the level of differentiation for the learners. As there are mainly mixed-ability pupils for music classes in schools in England, there was a need for further differentiation. The teacher suggested to introduce differentiated learning outcomes: low, intermediate, high. Therefore, we defined learning outcomes in three tiers: the lowest for all, intermediate for most and high for some pupils. So, all learners will reach the baseline learning outcome, most learners will reach the 
intermediate, which is a higher level than the baseline, and some learners will get beyond the average.

The lesson content in the teacher's pack is presented in a step-by-step procedure which was seen as very useful. Further suggestions were made by splitting this into Starter, Main and Plenary to make the lesson structure smoother. Positive feedback was received on the cross-curricular activities as this would enable teachers to use EARS 2 for a project day rather than exclusively for music lessons. Furthermore, the teacher suggested to have an extension activity to support more able learners. Finally, the teacher suggested to add an overview of the skills the learners would acquire; thereby presenting a rationale for teaching this project.

The teacher study pack, using the user-centred design process found that the guiding principles as outlined in 'ideate' were effective, especially after the refinement stage, which took on board the feedback.

\section{A new model for an inclusive music curriculum}

User-centred design allowed us to develop meaningful resources enabling teachers to create music lessons independent of the level of cultural capital of their pupils. The crucial tenant of Bourdieu's (1976) argument concerning social class was to understand that it is not exclusively based on materiality or wealth, but rather it is exacted through social knowledge: 'cultural capital' and 'habitus'. The privileging of high culture has led to a number of critiques of cultural reproduction along social class lines in the curricula as noted by the successors of the Frankfurt school (op.cit.). This was extended by Hargreaves' (1989) identification of the hegemonic academic curriculum. However, the resilience of the state to tenaciously maintain its grip on a traditional academic canon, has not only continued, but has been reaffirmed anew with Gove's curricular reforms (DfE 2013). By using a different approach to develop teaching materials, we challenge the traditional music curriculum to be more inclusive and not to depend on prior cultural capital. 


\subsection{The evolution of building an educational knowledge base for sound-based music}

Following on from inclusive ways to develop appropriate pedagogic content knowledge for incorporation into the teacher's packs, we developed a model describing the evolution of the knowledge domains in the EARS projects:

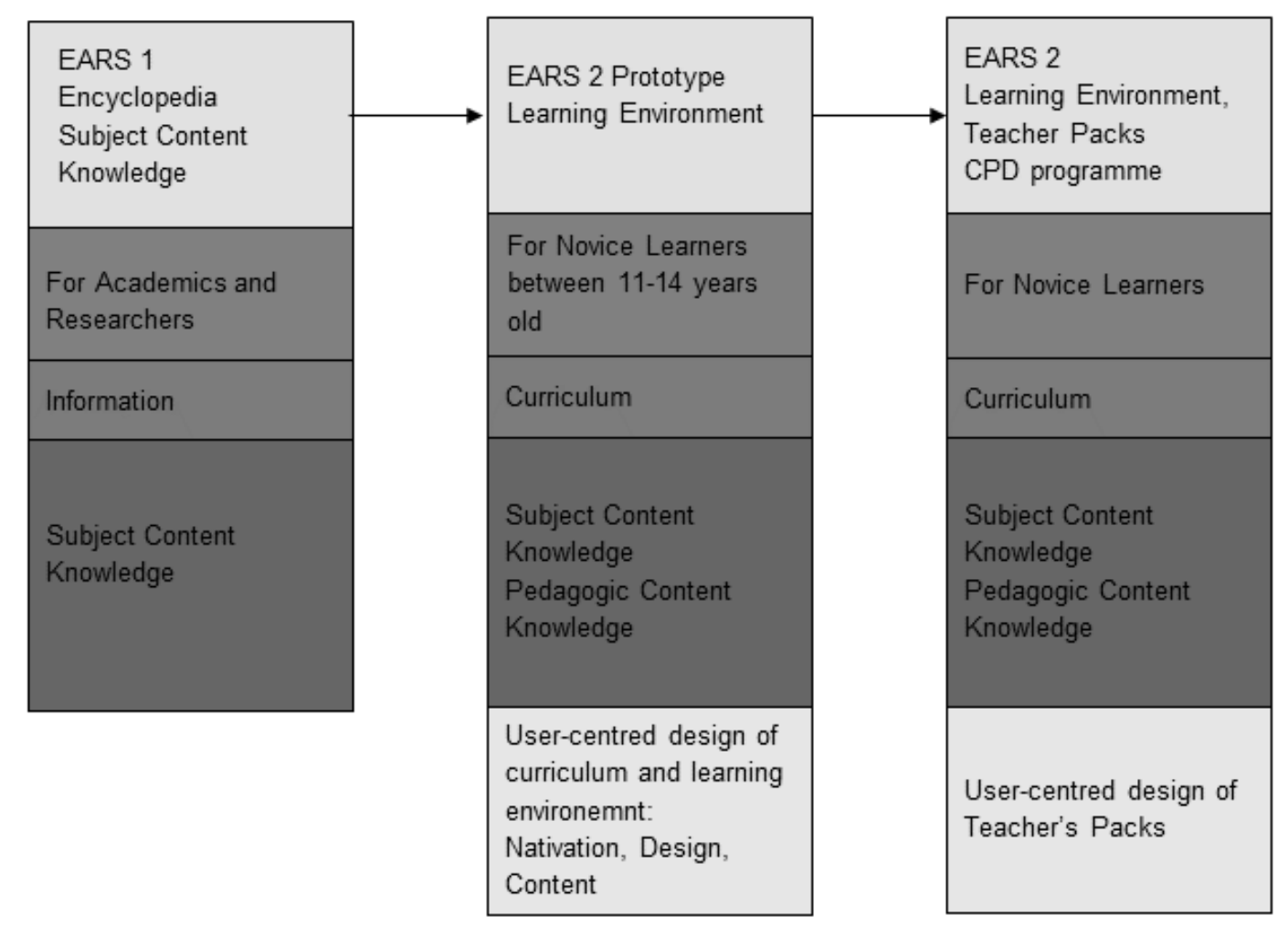

Figure 6: Model 1: Evolution of building an educational knowledge base for sound-based music

However, this model is widely applicable whenever new subject areas are discovered and interpreted for pedagogical application. 


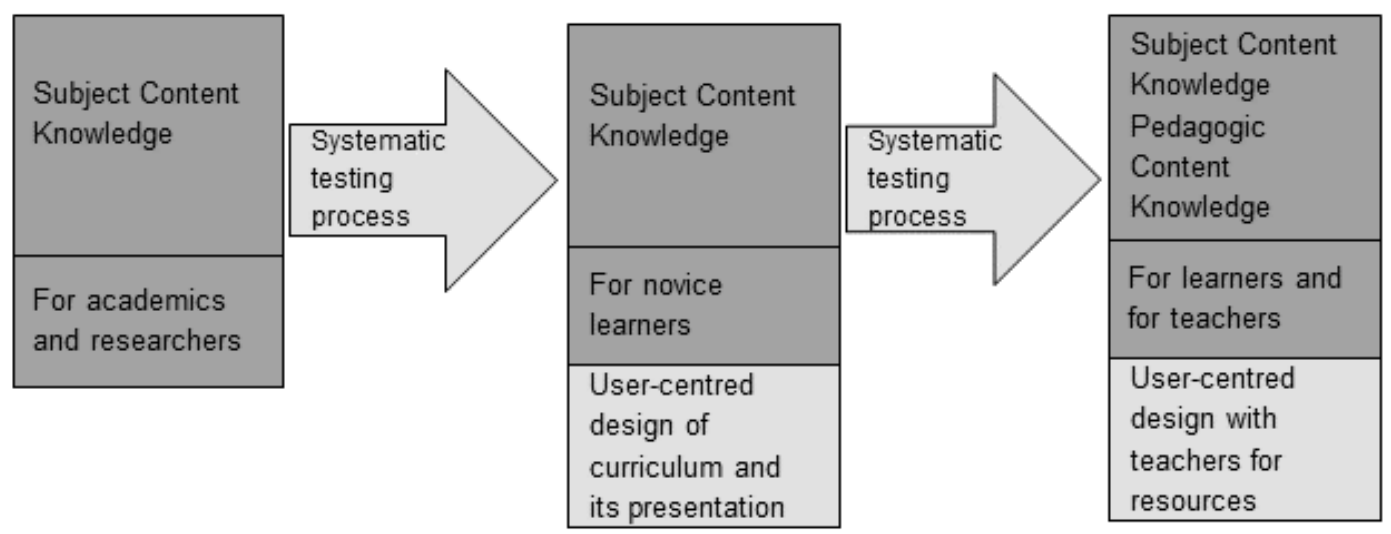

Figure 7 Model 2: Model of developing pedagogic content knowledge in a new field/subject

Masuhara (2011: 262) introduces various different models for the development of teaching materials. However, he criticises that 'the users [...] have little control over how their needs and wants are realised in the materials they use'. In response to this, we argue that the development of teaching materials works best following an inclusive approach using UCD. This thereby gives users a voice which Tomlinson (2011) argues is often ignored in the development of teaching materials. Following this innovative model, it is more likely that the content knowledge, the pedagogic content knowledge and where applicable TPACK, are relevant and meaningful to pupils and teachers.

\subsection{Innovation: disseminating educational research on sound-based music} From our analysis of the teacher knowledge required to teach sbm, we understand that teachers require subject content knowledge (SCK) of sbm (as developed in EARS 1) and pedagogic content knowledge (PCK) (as developed for the EARS 2 website and teacher's packs) and TPACK. For effective delivery in the classroom we found it necessary to provide further scaffolding through CPD, such that teachers develop the necessary metacognitive knowledge and cognitive prototypes for sbm to be able to teach sbm effectively to pupils (Wolf and Younie, 2018). 
Given the complexity of the development of SCK and PCK and TPACK within the area of teaching sbm, it is apparent that this is a new multi-faceted research area. Therefore, a further method of dissemination is necessary focusing on this research and making it accessible to teachers. This can be disseminated to teachers through research summaries, called MESHGuides, where MESH stands for 'Mapping Education Specialist knowHow' and are developed following the same guiding principles that led the teacher's pack development.

MESHGuides are a summary of research used to update and inform teacher's practice. This can include anything from new pedagogic knowledge to introducing new subject areas. MESHGuides can be understood as providing a bridge between research (academics/subject experts) and practice (teachers in schools). This is the process of translating research findings into practical applications (translational research), which originated in the field of science and medicine, but is little developed in education (Jones, Procter and Younie 2015). The MESHGuides are published online as flowcharts

allowing teachers to access the most up-to-date research and pedagogy in their subject (www.meshguides.org.uk). This addresses the United Nations' Sustainable Development Goal (SDG) 4c of 'improving education' by enabling teachers to access the latest subject expertise and pedagogic innovations. A series of Music MESHGuides are currently being prepared.

\section{Conclusions}

This paper has shown a systematic process for developing the different knowledge domains required for teaching a new subject area. Thereby, this paper adds to the epistemological discussion of the development of teaching materials for professional practice. The paper also addresses international transferability: as the model includes user-centred design, it has teachers and pupils in the centre of the development process. Hence, any cultural differences in subject content knowledge or pedagogic content knowledge can be taken into account through this inclusive approach. 
Therefore, if the development of the knowledge domains is carried out following an inclusive process (as in UCD), teachers will be more likely to use the resource, through engendering 'ownership'. In this specific case of sbm, where teachers are novices to the field, we ensure that the materials are understandable and usable as the teacher has to develop SCK, PCK and TPACK.

With EARS 2, a new subject area has been developed in music. Research has shown that this has pedagogic potential (see section 2). To reach the pupils, via the teachers delivery, pedagogic content knowledge has to be developed. Adopting a user-centred design approach ensured that teachers and pupils had a voice and were empowered to contribute to the development of the teaching materials; whereby we engendered communicative action (Habermas 1984, 1987). Sbm has been found to facilitate higher engagement in music with pupils. Hence involving teachers in developing the resources, makes it more likely that the new subject area is taught.

Through the analytical lens of critical theory, originating from the Frankfurt School and later Bourdieu (1976), we argue that sbm has the potential to actively and radically disrupt the traditional academic music curriculum that is dominated by high culture, which in turn privileges those from the middle classes. The greater cultural capital of middle-class pupils and their habitus affords them greater knowledge of the music canon, thereby privileging them in such a way as to reproduce existing cultural inequalities. However, sbm by not requiring any prior musical knowledge creates a level playing field, thereby significantly widening participation in music and enhancing music access for all pupils.

To realise this vision above of 'opening up music' through sbm depends on training teachers in this innovative sbm curriculum. Teachers need different types of professional knowledge to do this: new subject content knowledge (SCK) in sbm and importantly, also new pedagogic content knowledge (PCK), plus TPACK. 
The model outlined in this paper is an innovation in music teaching that is supported through a CPD programme and teacher resource packs, disseminated through Music MESHGuides (MMGs). This gives teachers globally the opportunity to engage in smb to enhance music access for all pupils. Subsequently, we address the UN Sustainable Development Goal (SDG) 4c 'to improve the quality of education', through enhancing music teaching in a way that is does not depend on any prior musical knowledge or cultural capital and instead enables the teaching of music to be fully inclusive for all pupils.

However, while we are disrupting and radically changing the way of thinking about music in school, we see this as a positive and healthy challenge. In this light, we provide a solution of widening access to music through this systematic, research-based model. This way, we provide scaffolding for a paradigm shift in music teaching. 


\section{References}

Adorno, T. W. 1970. Aesthetic Theory. London: Routledge.

Adorno, T. W. 1991. The Culture Industry: Selected Essays on Mass Culture. London: Routledge.

Albert, Daniel J. 2006. "Socioeconomic Status and Instrumental Music: What Does the Research Say about the Relationship and Its Implications?" UPDATE: Applications of Research in Music Education 25 (1): 39-45.

Anderson, L., Krathwohl, D. et al. (eds.) 2001. A Taxonomy for Learning, Teaching and Assessing, New York: Longman.

Bolton, J. 2008. Technologically mediated composition learning: Josh's story. British Journal of Music Education 25 (1): 41-56.

Bourdieu, P. 1976. The school as a conservative force: scholastic and cultural inequalities. In R. Dale, G. Esland, M. MacDonald (eds) Schooling and Capitalism. London: Routledge and Kegan Paul, and the Open University Press.

Bourdieu, P. 1977. Outline of a Theory of Practice. Cambridge: Cambridge University Press.

Bowles, S. and Gintis, H. 1976. Schooling in Capitalist America. New York: Basic books.

Brown, S. 2008. Complexity, Ambiguity And Uncertainty: A User-Centred Approach To Maximising Access And Use Of Event-Based Cultural Heritage Data. In: M. Ioannides, A. Addison, A. Georgopoulos, L. Kalisperis (eds.) VSMM 2008: Digital Heritage Proceedings of the 14th International Conference on Virtual Systems and Multimedia Short Papers, 102-8. Cyprus, 20-25 October 2008. 
Bruner, J. S. 2006. In Search of Pedagogy Volume 1: The Selected Works of Jerome S. Bruner. London: Routledge

Burnard, P. 2007. Reframing creativity and technology: promoting pedagogic change in music education. Journal of Music, Technology and Education, 1 (1): 37-55.

Capel, S., Leask, M. and Younie, S. (eds) 2016. Learning to Teach in the Secondary School: A Companion to School Experience. 7th edn Abingdon: Routledge.

Chan, K. and Yung, B. 2018. Developing Pedagogical Content Knowledge for Teaching a New Topic: More Than Teaching Experience and Subject Matter Knowledge. Res Sci Educ 48:233-65.

d.school. 2010. An introduction to design thinking: Process guide, Retrieved from https://dschool-old.stanford.edu/sandbox/groups/ designresources/wiki/36873/attachments/74b3d/ModeGuideBOOTCAMP2010L.pdf .

DfE (Department for Education) 2013. National Curriculum in England: Complete Framework for Key Stages 1 to 4 - for Teaching from September 2016, viewed 3 March 2019, from https://www.gov.uk/government/publications/national-curriculum-in-englandframework-for-key-stages-1-to-4.

DfE, 2011. The importance of music: a national plan for music education. Available from: https://www.gov.uk/government/publications/the-importance-of-music-a-nationalplan-for-music-education (accessed 20 March 2019)

Gilroy, P. 1987. There ain't no black in the Union Jack, London: Hutchinson.

Giroux, H. 1983. Theory and Resistance in Education. New York: Bergin and Garvey. 
Griffiths, A. (under review) Playing the White Man's tune: inclusion in elite classical music education. Article.

Habermas, J. 1984. The Theory of Communicative Action. Volume 1. Reason and Rationalisation of Society, trans. T. McCarthy. Cambridge: Polity Press/Basil Blackwell.

Habermas, J. 1987. The Theory of Communicative Action. Volume 2. Lifeworld and system, trans. T. McCarthy. Cambridge: Polity Press/Basil Blackwell.

Hargreaves, A. 1989. Curriculum and Assessment Reform. Oxford: Basil Blackwell.

Holland, D. 2016. Developing heightened listening: a creative tool for introducing primary school children to sound-based music. Ph.D. e-thesis, De Montfort University, Leicester. Available from: https://www.dora.dmu.ac.uk/handle/2086/13304

Horkheimer, M. 1938. Traditional and Critical Theory. In Critical Theory: Selected Essays. New York: Herder and Herder.

Jaramillo, M. C. J. 2008. The Music Educator's Professional Knowledge. Music Education Research 10(3): 347-59.

Jones, S., Procter, R, and Younie, S. 2015. Participatory Knowledge Mobilization: An emerging model for translational research in Education. JET Journal of Education for Teaching: international research and pedagogy; translational research and knowledge mobilisation in teacher education, Special Issue, 41 (5): 555-74.

Krug, S. 2000. Don't make me think! A common sense approach to web usability. Berkley: Newriders.

Landy, L. 2007. Understanding the Art of Sound Organization. Cambridge, MA: MIT Press. 
Landy, L. 2012. Making Music with Sounds. New York: Routledge.

Landy, L., Hall, R. and Uwins, M. 2013. Widening participation in electroacoustic music: The EARS 2 pedagogical initiatives. Organised Sound 18 (2): 109-23.

Landy, L., Younie, S., Hill, A. and Wolf, M. 2014. The EARS 2 Pedagogical Project: an eLearning environment to introduce learners to sound-based music. In: Himonides, E. \& King, A. (Eds.). 2014. Researching Music, Education, Technology: Critical Insights.

Proceedings of the Sempre MET 2014, London: International Music Education Research Centre (iMerc) Press. pp. 129-35.

Marcuse, H. 1937. The Affirmative Character of Culture. In Negations: Essays in Critical Theory. Boston, MA: Beacon press.

Masuhara, H. 2011. 'What do teachers really want from coursebooks?' in Tomlinson, B. (Ed) Materials Development in Language Teaching, Cambridge: Cambridge University Press, pp. 236-266.

McNiff, J. and Whitehead, J. 2010. You and Your Action Research Project, $3^{\text {rd }}$ edn, London: Routledge.

Mishra, P. and Koehler, M. J. 2006. Technological Pedagogical Content Knowledge: A Framework for Teacher Knowledge. Teachers College Record 108 (6), pp. 1017-54.

Pope, S. T. 1996. A Taxonomy of Computer Music. Contemporary Music Review 13(2): $137-45$.

Poulantaz, N. 1975. Classes in Contemporary Capitalism. London: New Left Books.

Savage, J. 2005. Working towards a theory of music technologies in the classroom: how pupils engage with and organise sounds with new technologies. 
British Journal of Music Education 22(2): 167-80.

Shivers-McNair, A. et al. 2018. User-Centered Design In and Beyond the Classroom: Toward an Accountable Practice. Computers and Composition 49: 36-47.

Shulman, L.S. 1986. Those who understand: Knowledge growth in teaching, Educational Researcher 15 (2): 4-14.

Tate Gallery's Movie Project 2011: https://www.tate.org.uk/about-us/projects/tate-movieproject

Therapontos, N. 2013. Evolving Music Education in the Digital Age: Sound-Based Music in Public Schools of Cyprus. PhD-E-thesis. De Montfort University. Available from: http://hdl.handle.net/2086/11609

Tomlinson, B. (Ed) 2011. Materials Development in Language Teaching, Cambridge: Cambridge University Press.

Valenzuela, R. and Codina, N. 2014. Habitus and flow in primary school musical practice: relations between family musical cultural capital, optimal experience and music participation. Music Education Research, 16 (4): 505-20.

Vincent, C., \& Ball, S. J. 2007. "Making up" the middle-class child: Families, activities and class dispositions. Sociology, 41(6): 1061-1077.

Walby, S. 1990. Theorizing Patriarchy, Oxford: Blackwell.

Willis, P. 1977. Learning to Labour. London: Saxon House.

Wolf, M. 2008. EARS II - Time for a new Approach to electroacoustic Music. In Marin, M. M., Knoche, M., \& Parncutt, R. (Eds.) First International Conference of Students of 
Systematic Musicology (SysMus08): Proceedings, Graz: Department of Musicology, University of Graz.

Wolf, M. 2013a. The Appreciation of Electroacoustic Music - An Empirical Study with Inexperienced Listeners, PhD E-thesis. Available from:

https://www.dora.dmu.ac.uk/xmlui/handle/2086/8680

Wolf, M. 2013b. The Appreciation of Electroacoustic Music - The Prototype of the pedagogical ElectroAcoustic Resource Site. Organised Sound 18 (2): 124-133.

Wolf, M. and Younie, S. 2018. Overcoming barriers: towards a framework for Continuing Professional Development to foster teaching sound-based music. Journal of Music, Technology and Education 11 (1): 83-101.

Younie, S. 2007. Integrating ICT into Teachers Professional Practice: the cultural dynamics of change. PhD thesis. De Montfort University, Leicester. 